\title{
Organization of public private partnership in the renovation of urban areas
}

\author{
Anastasiia Obraztsova ${ }^{1, *}$, Ludmila Kamenik ${ }^{1}$ \\ ${ }^{1}$ Peter the Great Saint- Petersburg Polytechnic University, Polytechnicheskaya str., 29, Saint- \\ Petersburg, 195251, Russia
}

\begin{abstract}
Currently, renovation of industrial areas and search for its organization forms has become a pressing issue for many cities. The introduction of public private partnership as a new form of organization in this sphere encountered the lack and need of consideration of the social factor. Today, this problem is a serious obstacle to the implementation of this type of organization of development of industrial areas of the city. At the same time, none of the existing methods of investment project evaluation, including those implemented under public private partnerships, provides for a comprehensive evaluation of the social factor. Ignoring this kind of evaluation will result in capital risk, higher costs and increased time to complete projects. The authors propose to consider a methodology for evaluating the utilization efficiency of former industrial areas, which is based on principles of integral assessment which includes the social factor. The result of the author's methodology is that it: will, in view of the social factor, determine the amount of total investment as the sum of costs before entering contracts. Investment cost estimation in this case will cease to be spontaneous, while the process of construction organization becomes manageable.
\end{abstract}

\section{Introduction}

Cooperation of public partner and private investors is applicable to increasingly wider range of social and industrial aspects of the city. However, in the Russian Federation, the legal framework to regulate these relations has just started development and coordination of the relevant federal documents and regulations at the level of federal subjects of the Russian Federation. Proper interface management is a prerequisite for creating an effective investment policy, taking into account the balance of interests between the state, private business and the general public. The interface of public authorities and the private sector in public private partnership (hereinafter - PPP) in the Russian Federation is becoming more widely used, including in renovation of urban areas. However, practice shows that the question of costs related to the social factor arises after the determination of the investment volume, and social implications (which are sometimes crucial) appear in the course of work, and it is not always clear who should pay for them. Thus, investment costs originate spontaneously. In the current situation, it can be concluded as follows: organization of

\footnotetext{
${ }^{*}$ Corresponding author: obrastcova.anastasiia@yahoo.com
} 
application of PPP model for renovation of areas requires a new approach due to belated and insufficient response to the social factor. This is one of the causes of investment risk, and therefore study of this point is deemed to be of particular current interest.

A dominant role of private investment suggests a shift in focus of investment activity regulation by the state from the distribution function of public investment to increasing the investment potential taking into account the social factor, which is of particular importance in the organization of construction work.

The analysis logic in the current situation demonstrates the need for change in the methodological approach to the development of PPP model in the sphere of renovation of industrial areas. The new methodological approach should be based on a systematic approach involving the full cost of the entire renovation cycle, taking into account any social consequences of the project. Social factor costs should be distributed between all members of the investment project equitably, and not be only borne by the state, which is the case now, or leads to cancellation of PPP project arrangements completely. Misalignment of interests for this issue results in recall of investment projects. A model equitable methodologically should be the basis of relations aimed at alignment of interests of all participants in the investment process.

The PPP process in general is a specific form of relations between the state and private enterprises, which is used to solve specific problems, and it is currently in demand. Thus, from a theoretical and practical perspectives, it is of particular interest to analyze its formation and development trends in Russia. Let us briefly look into the background [1].

V.V. Prokhorov in his book 'Public Private Partnership: Case History and Application Potential' turns to the origin of PPP forms and mechanisms in Russia, going into particular details of the history of development of railroad transportation service in the Russian Empire and financial arrangements of this type of projects. When considering the current situation and forms of the state and private sector partnership, the author backed them with examples of implementation of concessionary agreements involving St. Petersburg, mentioning advanced experience of the city [2].

The global experience in the formation of PPP is also discussed in the study of D.B. Matveyev 'Public Private Partnership: Foreign and Russian Experience.' The author dwells on the legal framework of partnership. The book provides examples of successful projects in the United States, several European countries, the China's advanced experience, and also the problems and prospects of concessions and other forms of PPP in Russia through the example of Soviet-era concessionary agreements [3].

The positive experience in the implementation of the government efforts in the development of the regulatory and legal environment for PPP, through the example of the UK and Ireland, is presented in the study of V.A. Kabashkin and O.M. Malakhaeva 'Public Private Partnership in the UK and Ireland' [4]. The level of PPP development nowadays is quite heterogeneous in different countries of the world. This is evidenced by such indicators as: the degree of elaboration of the legal framework, the scope of application of public private and municipal-private partnership arrangements, a variety of organizational and legal forms of cooperation between the state and the private sector. Also, the active cooperation between public authorities and business in Russia in the implementation of socially important infrastructural projects at different levels — federal, regional and municipal - is more discernible now.

Among researchers who discuss the assessment of PPP efficiency, we would like to turn our attention to studies of A. Akintoye, who, along with a review of global experience in the implementation of infrastructure projects under PPP [5-9], and with assistance from M. Beck and C.Hardcastle addresses the problems of risk management at all stages of project implementation. In particular, one of the aspects of risk management is the investment risk $[10,11]$. 


\section{Methodology}

The primary document to regulate relations in the field of PPP in the Russian Federation is the Federal Law No. 224-FZ 'On public private partnership, municipal-private partnership in the Russian Federation and introducing amendments to certain legislative acts of the Russian Federation' dated 13.07.2015 (hereinafter - the Federal Law), and effective from January 01, 2016.

For the purpose of implementation of the Federal Law, the Ministry of Economic Development of the Russian Federation issued the Order No. 894 dated 30.11.2015 to enforce the Methodology for evaluating the efficiency of public private partnership project and municipal-private partnership project, involving the determination of their comparative advantage (hereinafter - the Methodology) [12]. According to section IV of the Methodology, social and economic efficiency of a project is based on consistency of the goals, objectives and project performance with values of not less than two targets of state (municipal) programs, accordingly [13]. This approach to the evaluation is generalized in nature and not focused on the industry specific features, which describing industry specific features necessitates the development of industry practices. This is determined the need for independent development of a methodology for evaluating the utilization efficiency of urban areas, in particular, former industrial areas, taking into account the specific features of the process.

The authors of this article propose to introduce 2 classifications of urban areas as follows. The first classification is based on functionality and allows for dividing the whole array of urban areas into two main groups: industrial areas and residential, public and commercial areas, including the recreation, road transport and utilities infrastructure. The second classification is based on management levels and managerial decision-making and includes urban and municipal levels of territory management.

Given the distinctive characteristics of different types of areas and differences in management principles, all the areas have a common feature, which is represented by the need to consider the social factor in the analysis of urban land use projects: renovation, modernization and rehabilitation of territories. However, this factor is currently poorly elaborated, which result in increased capital risk.

A good example of increase in capital risk, risk of deadline disruption and project cost against the social factor is the Okhta Center cultural and business complex project. The project was supposed to be implemented by Okhta Cultural and Business Center JSC on the land plot of 47.253 sq. m. But it encountered resistance. First, the arguments of experts and residents revolved around the allowable deviation from limiting parameters in permitted construction of high-rise dominant building [14]. Second, due to archaeological finds on the construction site [15]. These debates were accompanied by intervention of community activists and historic preservation activists. In December 2010, it was decided to cancel the construction of cultural and business complex on the bank of the Neva River and to start negotiations to find alternative land for the project.

It can be stated as follows: at the time of cancellation, the investment in the cultural and business complex project were estimated by the investor as 7.2 billion rubles. No decision on the suspended construction site was taken. Implementation of the project which is referred to today as "Lakhta Center" was moved to a different location, and the construction work is already close to completion.

The social factor, in this case rather pronounced, was ignored. The negative result was predetermined by omitting analysis of public opinion and a preliminary assessment of social consequences.

For a more insightful analysis of the social factor, the authors propose to consider the Methodology for evaluating the utilization efficiency of former industrial areas, which is 
focused on the principles of application of the PPP mechanisms, taking into account the features specific to industrial area renovation projects. It is the authors' opinion that, evaluation under the methodology can be performed on the basis of integral assessment. Integral assessment is assessment which reflects the aspirations of PPP process stakeholders to the limit of their own interests, but is implemented on the basis of the balance of common interests. This type of assessment considers project efficiency as an inextricably intertwined, one-piece, single process of project implementation. Integral assessment presents the advantages of implementation of renovation projects in relation to the current use of the existing facility in a unified form. The assessment relies upon consideration of qualitative and quantitative characteristics of renovation projects.

The criteria for the integral assessment of industrial area renovation projects to be developed should be based on the following principles: the principle of a systematic approach to include the costs of the entire construction cycle; the need to consider the specific features of the renovation project; the need to consider the specific features of the production process; the need to consider the structural complexity of the renovation project (land, capital facilities, utilities); the need for an integrated approach (economic, environmental and social factor); division of the criteria into qualitative and quantitative criteria; use of cross-cutting approach in the calculation of integral assessment of efficiency (for all participants in the project).

Considering the structural variety of facilities proposed for renovation for the purposes of the Methodology for evaluating the utilization efficiency of former industrial areas, it is advisable to adopt, for all the facilities under consideration, a division into two interrelated components: land and capital facilities. This principle is also based on cross-cutting approach used in the development of efficiency evaluation criteria. Its peculiarity is in the fact that a number of criteria, in particular qualitative criteria, are rated on a unified scale that applies to all facilities, regardless of their size and geographic location. The unified scale is a numerical score from 0 to 1 (with rounding to the nearest tenth, if required), which is calculated for each criterion in accordance with the parameters of the facility proposed for consideration.

Evaluation of the results of the project is carried out with 2 groups of indicators: quantitative and qualitative. In this regard, the whole set of evaluation criteria in the projected Methodology for evaluating the utilization efficiency of former industrial areas includes 2 groups of criteria: qualitative and quantitative criteria for evaluation of the outcome.

Efficiency evaluation is based on the following qualitative criteria:

1. Alignment of interests of the public and private partners within the proposed project;

2. Consideration of the social factors;

3. Compliance with environmental standards;

4. Compatibility of the technology in use with best available technology.

Thus, the score for renovation efficiency for the industrial area (the current use of facility) on the basis of qualitative criteria is calculated from the Equation proposed below:

$$
I_{q}=F_{S_{-} i}\left(F_{s_{-} j}\right)+F_{S c_{-} i}\left(F_{S C_{-} j}\right)+F_{\text {eco } \_}\left(F_{\text {eco } \_j}\right)+F_{t_{-} i}\left(F_{t_{-} j}\right)
$$

Where $F_{S_{-} i}\left(F_{S_{-} j}\right)$ - numerical score corresponding to the degree of alignment of interests of the public and private partners (land owner and/or enterprise) within the proposed project (the current use of the facility); $F_{s c_{-} i}\left(F_{s c_{-} j}\right)$ - numerical score that takes into account the social factors; $F_{\text {eco }} i\left(F_{\text {eco } j}\right)$ - numerical score corresponding to the degree of environmental compliance; $F_{t_{-} i}\left(F_{t_{-} j}\right)$ - numerical score representing compatibility of the technology used in the construction and operation with best available technology. 
The presented calculation is performed separately for evaluation of the proposed project and the current use of the existing facility, respectively.

Evaluation of utilization efficiency of former industrial area on the basis of quantitative criteria is performed according to the iterations shown below. At each stage, value of the index to measure certain characteristics of the new infrastructure facility is calculated, as well as the value of this index for existing. In accordance with expected value of the index, each criterion is assigned a specific assessment score $(F)$.

Financial and economic efficiency of renovation project with consideration of the social factor is calculated from the Equation of net present value $(N P V)$ :

$$
I_{\text {fin }_{-} i}=P I_{i}=\frac{N P V_{i}}{I C_{i}}
$$

Where $P I$ (Profitability Index) - index of profitability of the investment project; $N P V_{i}-$ net present value of the project; $I C_{i}$ - investment costs for the capital stage of the project, which include the cost of consideration of the social factor.

In calculating the cash flow $\left(C F_{i}\right)$, the operating expenses during the facility operation shall be considered $\left(\mathrm{CF}_{\text {expl }}\right)$.

A key feature of the calculation of cash flow $\left(C F_{i}\right)$ during operation of the proposed facility under PPP project is the proceeds from the private partner. Since the public partner acts as a guarantor of return of the funds invested by the investor at the capital stage, as well as the receipt of a minimum guaranteed income, in general terms, the proceeds for the period $t$, shall consist of the following components and can be calculated from the following Equation:

$$
\Pi_{i_{-} t}=\mathrm{K}_{c a p}+\mathrm{K}_{\text {expl }}+I N C=\mathrm{K}_{m}+\mathrm{K}_{s c}+\mathrm{K}_{\text {expl }}+I N C
$$

Where $\mathrm{P}_{\mathrm{i}_{t}}$ - proceeds from the operation of facility for the period of $t ; \mathrm{C}_{c a p}$ - payments by the public partner to compensate for expenses incurred by the investor at the capital phase of the project, which include the cost of consideration of the social factor; $\mathrm{C}_{\text {expl }}-$ amount of compensation for expenses incurred at the construction phase, including the cost of demolition, new construction and landscaping; $I N C$ - minimum guaranteed income.

Financial and economic efficiency of the current use (the existing facility) with no consideration of the social factor is calculated from the following Equation:

$$
I_{\text {fin } \_j}=\frac{P_{j}}{C_{j}}
$$

Where $P_{j}$ - total income from the economic activities of the enterprise (the land use); $C_{j}$ - total cost of the enterprise functioning, which include the following types of costs.

Calculation of the index of public demand for the proposed facility and the index of public demand for the existing facility (i.e., with consideration of the social factor). $I_{d e m_{-} i}-$ available consumers of services (goods) to be provided (created) as a result of operation of the proposed facility; $I_{d e m_{j} j \mathrm{p}}$ - available consumers of services (goods) provided (created) as a result of operation of the existing facility;

The score for renovation efficiency for the industrial area and the current use of facility on the basis of quantitative criteria is calculated from the Equation proposed below:

$$
I_{q u_{\_} i}\left(I_{q u_{\_} j}\right)=F_{f i n_{\_} i}\left(F_{f i n_{-} j}\right)+F_{\text {dem } \_i}\left(F_{d e m_{\_} j}\right)
$$

Where $F_{\text {fin }{ }_{-} i}\left(F_{\text {fin } \_j}\right)$ - numerical score determined in accordance with the calculated financial and economic efficiency with consideration of the social factor and the current use (the existing facility); $F_{d e m_{-} i}\left(F_{d e m_{-} j}\right)$ - numerical score determined in accordance with the 
calculated index of public demand for the proposed facility and the current use (the existing facility).

As a result of the evaluation of efficiency, with consideration of qualitative and quantitative criteria for the proposed facility with consideration of the social factor and the existing facility, the overall efficiency indexes are calculated from the following Equation:

$$
I_{i}\left(I_{j}\right)=I_{q_{-} i}\left(I_{q_{-} j}\right)+I_{q u_{\_} i}\left(I_{q u_{-} j}\right)
$$

Where $I_{\mathrm{i}}$ - utilization efficiency index for renovation of industrial facility with consideration of the social factor; $I_{\mathrm{j}}$ - utilization efficiency index for existing industrial facility.

Integral assessment of the industrial area renovation efficiency allows comparing the proposed (with consideration of the social factor) and the current uses of the industrial facility and area and is calculated as follows:

$$
I=\frac{I_{i}}{I_{j}}
$$

Where $I_{l}$ - utilization efficiency index for renovation of industrial facility with consideration of the social factor; $I_{j}$ - utilization efficiency index for existing industrial facility.

Thus, in this Equation, the integral assessment is generalization of the evaluation considered above. This is how the integral effect is achieved.

\section{Summary}

We can draw the following conclusions:

- The Methodology for evaluating the utilization efficiency of industrial areas with application of PPP principles will make it possible to make an in-depth assessment of the social factor that affect the project implementation processes. The integral assessment includes the value of total investment adjusted for the social factor;

- The Methodology for evaluating the utilization efficiency of industrial areas is a universal investment planning tool to be applicable at different levels of management all the way to the consideration of project documentation and identification of comparative advantages of the new construction project and to conclusion of agreements of cooperation in the framework of PPP.

- Organization of PPP for industrial area renovation projects will cease to be spontaneous, and will become more manageable, which reduces the implementation risks significantly. The interface of partners is based on an equitable model of relationship. No business can be successful until it is supported methodologically. This factor is of particular importance for the organization and planning of construction work and municipal funds.

\section{References}

1. A.S. Obraztsova, L.L. Kamenik, St. Petersburg State Polytechnical University Journal16(3), 255-261 (2016)

2. V.V. Prokhorov, Public Private Partnership: case history and application potential(SibSAU, Krasnoyarsk, 2014) 
3. D.B. Matveyev,Public private partnership: foreign and Russian experience (Nauka, St. Petersburg, 2009)

4. V.A. Kabashkin, O.M. Malakhaeva,Public Private Partnership in the UK and Ireland(International Innovation Center LLC,Moscow, 2010)

5. N. Carbonara, N. Costantino, R. Pellegrino, Public Private Partnership in Italy: State of art, Trends and Proposals ((Edt) Routledge, London, 2016)

6. D. Grimsey, M. Lewis, Public Private Partnerships: The Worldwide Revolution in Infrastructure Provision and Project Finance(Edward Elgar, Cheltenham, 2007)

7. J.M. Sarmento, L.Renneboog,Portugal Experience with Public Private Partnerships((Edt) Routledge, London, 2016)

8. M. Siemiatycki,Public Private Partnerships in Canada((Edt) Routledge, London 2016)

9. X.W. Zoup, R.J. Yang, PPP Applications in Australia Infrastructure Development ((Edt) Routledge, London, 2016

10. A. Akintoye, M. Beck, C.Hardcastle,Public Private Partnerships: Managing Risks and Opportunities (Blackwell Publishing Ltd, London, 2003)

11. A. Akintoye, M. Beck,Policy, finance \& management for public private partnerships(Blackwell Publishing Ltd, London, 2009)

12. Russian Federal Law No. 224-Ф3

13. Order No. 894(Ministry of Economic Development of the Russian Federation, Russia, 2015) 